\title{
Improving Concrete Durability by Using Optimized Aggregate Gradation and Reducing Cement Content
}

\author{
Hung-Wen Chung \\ chweying@ufl.edu \\ University of Florida, Department of Civil Engineering, Gainesville, Florida, USA \\ Thanachart Subgranon \\ tsubgranon@ufl.edu \\ University of Florida, Department of Civil Engineering, Gainesville, Florida, USA \\ Mang Tia \\ tia@ce.ufl.edu \\ University of Florida, Department of Civil Engineering, Gainesville, Florida, USA
}

\begin{abstract}
This study evaluated the effects of (1) reducing the cementitious content, (2) the use of optimized aggregate gradation (OAG) technique, and (3) the use of Portland limestone cement (Type IL) in Florida Class I pavement and Class IV structural concrete. The potential performance of the pavement concrete mixes was also evaluated using critical stress analysis using a 3D FEM model. The compressive strength, modulus of rupture, modulus of elasticity, Poisson's ratio, splitting tensile strength, coefficient of thermal expansion, rapid chloride permeability, and surface resistivity of the concrete mixes using normal Portland cement (Type I/II) and the concrete mixes using Type IL cement were similar to one another. The results of critical stress analysis indicated that the pavement concrete using Type IL cement had a predicted performance similar to concrete using Type I/II cement. The predicted performance of the pavement concrete was improved when the OAG technique was used. The main findings from this study are as follows: (1) The cementitious content of typical Florida pavement and structural concrete can be reduced by as much as 10 to $15 \%$ without loss in workability of the fresh concrete, and without decreasing the strength and durability of the hardened concrete. (2) Portlandlimestone cement (Type IL) can be used as a substitute for ordinary Portland cement (Type I/II). (3) The OAG technique can be used to efficiently reduce the cementitious content of the concrete mixes and to improve their performance.
\end{abstract}

Keywords: Optimized aggregate gradation; Portland-limestone cement; Cementitious content; Concrete pavement; 3D FEM model

\section{INTRODUCTION}

The concrete industry in Florida and in the U.S. is presently facing two major challenges, namely (1) the rising cost of cement and (2) the shortage of fly ash (ARTBA, 2015). One of the possible solutions to these challenges is using a more effective design method for concrete mixes, in which the cementitious materials content is minimized. Previous preliminary investigations have indicated that most FDOT concrete mixes have an excess of cement paste (Tia et al., 2015). In reality, $10 \%$ to $20 \%$ of the cement content in most FDOT concrete mixes could be removed without any adverse effects 
on the plastic or hardened concrete properties. This reduction in cement content can be maximized when using an intermediate-sized coarse aggregate along with the original aggregate. By adjusting the gradation of the coarse aggregate blend, an optimum packing of aggregate (optimum aggregate gradation, $\mathrm{OAG}$ ) can be obtained such that the aggregate volume is maximized. The use of OAG along with the reduction of paste (cement) content can improve the properties of the concrete mix, including (1) improved workability of fresh concrete, (2) reduced drying shrinkage, (3) increased resistance to intrusion of chlorides and sulfates (Singh, 2015), (4) reduced heat of hydration, (5) increased thermal conductivity, and (6) reduced coefficient of thermal expansion. The last three property improvements would greatly reduce the tendency for thermal cracking of the concrete (Tritsch et al, 2005).

Using Portland limestone cement (PLC) is an alternative way to decrease the cementitious content of concrete. In U.S., American Society for Testing and Materials (ASTM) allows the ordinary Portland cement (OPC) to contain up to 5\% limestone powder in ASTM C150 (ASTM, 2018(a)). According to ASTM C595, blended hydraulic cement can contain up to $15 \%$ limestone powder (ASTM, 2018(b)). The reduction in the use of cementitious materials would significantly reduce the cost of concrete and reduce the environmental impact by conserving natural resources, lowering energy consumption, and lowering carbon dioxide emission. This research study was conducted to address this need.

\section{LABORATORY TESTING PROGRAM}

A laboratory testing program was conducted to evaluate the effects of reducing cementitious material content, the feasibility of using Portland-limestone cement (Type IL), and the benefits of optimized aggregate gradation (OAG) technique on Florida Class I (Pavement) and Florida Class IV (Structural) concrete. The properties of the Type I/II and Type IL cements, which were used in this study are shown in Table 1. The Type I/ II cement passed the requirements of AASHTO M85 (AASHTO 2015) and the Type IL cement passed the requirements of AASHTO M 240M/M240 (AASHTO 2018).

\begin{tabular}{|c|c|c|c|}
\hline \multicolumn{2}{|l|}{ Test Items } & $\begin{array}{c}\text { OPC } \\
\text { (Type I/II) }\end{array}$ & $\begin{array}{c}\text { PLC } \\
\text { (Type IL) }\end{array}$ \\
\hline \multicolumn{2}{|l|}{ Air Content of Mortar ASTM C185 (\%) } & 4.10 & 8.00 \\
\hline \multicolumn{2}{|l|}{ Blaine Fineness ASTM C204 (m²/kg) } & 401.00 & 522.00 \\
\hline \multicolumn{2}{|l|}{ Fineness ASTM C430 (\%) } & 2.80 & 3.60 \\
\hline \multicolumn{2}{|l|}{ Autoclave expansion ASTM C151 (\%) } & 0.04 & -.01 \\
\hline \multicolumn{2}{|l|}{ Density of Cement ASTM C188 $\left(\mathrm{g} / \mathrm{cm}^{3}\right)$} & 3.20 & 3.16 \\
\hline \multicolumn{2}{|l|}{ Loss on Ignition ASTM C114 (\%) } & 2.00 & 5.60 \\
\hline \multicolumn{2}{|l|}{ Limestone (\%) } & 2.10 & 12.60 \\
\hline \multicolumn{2}{|l|}{ Time of Setting-initial ASTM C191 (minutes) } & 123.00 & 105.00 \\
\hline \multicolumn{2}{|l|}{ Heat of Hydration ASTM C1702 $(\mathrm{Cal} / \mathrm{g})$} & 65.00 & 65.40 \\
\hline \multirow{4}{*}{ Compressive Strength ASTM C109 (MPa) } & 1 day & 14.82 & 15.43 \\
\hline & 3 days & 26.82 & 26.23 \\
\hline & 7 days & 35.99 & 33.23 \\
\hline & 28 days & 49.99 & 44.29 \\
\hline
\end{tabular}

The mix designs of the pavement concrete mixes which were evaluated are shown in Table 2 . The necessary amounts of water-reducing and air-entraining admixtures were 
added to achieve the target slump of 0 to $5 \mathrm{~cm}$, and air content of 1 to $6 \%$. The reference pavement mix design is a commonly-used Florida Department of Transportation (FDOT)-approved pavement concrete mixture. The mix had a w/cm ratio of 0.44 and total cementitious materials content of $320 \mathrm{~kg} / \mathrm{m}^{3}\left(540 \mathrm{lb} / \mathrm{yd}^{3}\right)(80 \%$ Type I/II and $20 \%$ Class F Fly Ash). The cement paste volume (CPV) of the reference mix is $25 \%$, which meets the suggestion of AASHTO Designation PP 84-17. Based on the reference mix, twelve mix designs were developed to evaluate the effects of PLC concrete with OAG technique and reduced cementitious content. Paste contents investigated were 110, 100, 95,90 , and 85 percent (by weight) of the reference paste quantity of the mixture. Three groups of concrete mixtures were developed. The first group is designated as the SC group which used Type I/II cement of various cement contents. The second group is designated as the LC group which used PLC of various cement contents. The last group is designated as the OLC group which used OAG and PLC of various cement contents. A total of thirteen mix designs, and two batches per mix design were evaluated.

\begin{tabular}{|c|c|c|c|c|c|c|}
\hline $\begin{array}{c}\text { Mix } \\
\text { Design }\end{array}$ & $\begin{array}{l}\text { Paste } \\
\text { Volume } \\
(\%)\end{array}$ & $\begin{array}{l}\text { Cement } \\
\left(\mathrm{kg} / \mathrm{m}^{3}\right)\end{array}$ & $\begin{array}{l}\text { Fly Ash } \\
\left(\mathrm{kg} / \mathrm{m}^{3}\right)\end{array}$ & $\begin{array}{c}\text { Fine } \\
\text { Agg. } \\
\left(\mathrm{kgg} / \mathrm{m}^{3}\right)\end{array}$ & $\begin{array}{c}\text { Intermediate } \\
\text { Agg. } \\
\left(\mathrm{kg} / \mathrm{m}^{3}\right)\end{array}$ & $\begin{array}{c}\text { Coarse } \\
\text { Agg. } \\
\left(\mathrm{kg} / \mathrm{m}^{3}\right)\end{array}$ \\
\hline SC110* & 27.5 & 281.9 & 70.5 & 785.1 & 000.0 & 0985.0 \\
\hline $\mathrm{SC}$ & 25.0 & 256.3 & 64.1 & 805.4 & 000.0 & 1013.0 \\
\hline SC95 & 23.7 & 243.5 & 60.9 & 828.1 & 000.0 & 1038.5 \\
\hline SC90 & 22.5 & 230.7 & 57.7 & 835.0 & 000.0 & 1047.3 \\
\hline LC110 & 27.5 & 281.9 & 70.5 & 781.2 & 000.0 & 0983.4 \\
\hline LC100 & 25.0 & 256.3 & 64.1 & 811.3 & 000.0 & 1020.0 \\
\hline LC95 & 23.7 & 243.5 & 60.9 & 834.9 & 000.0 & 1037.7 \\
\hline LC90 & 22.5 & 230.7 & 57.7 & 838.9 & 000.0 & 1055.6 \\
\hline OLC110 & 27.5 & 281.9 & 70.5 & 581.9 & 359.5 & 0827.6 \\
\hline OLC100 & 25.0 & 256.3 & 64.1 & 632.9 & 363.0 & 0839.5 \\
\hline OLC95 & 23.7 & 243.5 & 60.9 & 660.7 & 362.4 & 0845.2 \\
\hline OLC90 & 22.5 & 230.7 & 57.7 & 686.0 & 366.4 & 0851.0 \\
\hline OLC85 & 21.5 & 217.9 & 54.5 & 711.3 & 366.6 & 0853.7 \\
\hline
\end{tabular}

*Number after mix type indicates \% relative cementitious content as compared to the reference mix.

For the SC and LC mixes, the aggregate blend was obtained by combining a size 57 coarse limestone aggregate with a nominal maximum size of $25 \mathrm{~mm}(1 \mathrm{inch})$ with a silica sand with fineness of 2.45. The resulting aggregate blend was a gap-graded aggregate. For the OLC mixes, the aggregate blend was obtained by combining the same size 57 coarse limestone aggregate and the same silica sand with an intermediatesize 89 limestone aggregate with a nominal maximum size of $9.5 \mathrm{~mm}(3 / 8 \mathrm{inch})$ using the Coarseness Factor Chart developed by Shilstone (Shilstone 1990). The resulting aggregate blend is a well-graded aggregate with good workability.

The mix designs of the structural concrete mixes which were evaluated are shown in Table 3. The necessary amounts of water-reducing and air-entraining admixtures were added to achieve the target slump of 5 to $10 \mathrm{~cm}$, and air content of 1 to $6 \%$. The reference mixture design is an industrial mixture approved by FDOT. The concrete mix had a w/ $\mathrm{cm}$ ratio of 0.40 , and total cementitious materials content ( $80 \%$ Type I/II and $20 \%$ Class F Fly Ash) of $346.5 \mathrm{~kg} / \mathrm{m}^{3}$. The average cement paste volume of the reference mix is 
$32.0 \%$. Based on the reference mix, twelve mix designs were developed to evaluate the effects of PLC concrete with OAG technique and reduced cementitious content. Paste contents investigated were 110,100, 85 and 75 percent (by weight) of the reference paste quantity of the mixture. A total of thirteen mix designs, and two batches per mix design were evaluated.

Table 3: Mixture Proportions Structural Concrete Mixtures

\begin{tabular}{lccccc}
\hline $\begin{array}{c}\text { Mix } \\
\text { Design }\end{array}$ & $\begin{array}{c}\text { Cement } \\
\left(\mathrm{kg} / \mathrm{m}^{3}\right)\end{array}$ & $\begin{array}{c}\text { Fly } \\
\text { Ash } \\
\left(\mathrm{kg} / \mathrm{m}^{3}\right)\end{array}$ & $\begin{array}{c}\text { Fine } \\
\text { Agg. } \\
\left(\mathrm{kg} / \mathrm{m}^{3}\right)\end{array}$ & $\begin{array}{c}\text { Intermediate } \\
\begin{array}{c}\text { Agg. } \\
\left(\mathrm{kg} / \mathrm{m}^{3}\right)\end{array}\end{array}$ & $\begin{array}{c}\text { Coarse } \\
\text { Agg. } \\
\left(\mathrm{kg} / \mathrm{m}^{3}\right)\end{array}$ \\
\hline SC110* & 381.1 & 95.3 & 598.7 & 0.0 & 965.9 \\
SC100 & 346.5 & 86.6 & 623.8 & 0.0 & 1008.7 \\
SC85 & 294.5 & 73.6 & 673.1 & 0.0 & 1088.7 \\
SC75 & 259.9 & 65.0 & 706.5 & 0.0 & 1131.6 \\
LC110 & 381.1 & 95.3 & 584.3 & 0.0 & 943.7 \\
LC100 & 346.5 & 86.6 & 627.4 & 0.0 & 1015.3 \\
LC85 & 294.5 & 73.6 & 657.6 & 0.0 & 1065.1 \\
LC75 & 259.9 & 65.0 & 687.7 & 0.0 & 1113.4 \\
OLC110 & 381.1 & 95.3 & 410.6 & 143.5 & 974.4 \\
OLC100 & 346.5 & 86.6 & 445.0 & 437.1 & 717.2 \\
OLC85 & 294.5 & 73.6 & 550.6 & 150.8 & 1026.2 \\
OLC75 & 259.9 & 65.0 & 592.9 & 455.3 & 749.7 \\
\hline
\end{tabular}

*Number after mix type indicates \% relative cementitious content as compared to the reference mix.

The tests on fresh concrete were carried out in accordance with ASTM C143 (Slump), AASHTO PP84-17 (Box Test), ASTM C231(Air Content), ASTM C138 (Unit Weight), ASTM C1064 (Temperature), and ASTM C232 (Bleeding). The strength tests on hardened concrete included ASTM C39 (Compressive Strength), ASTM C78 (Modulus of Rupture), ASTM C496 (Splitting Tensile Strength), and ASTM C469 (Modulus of Elasticity and Poisson's Ratio). Concrete cylindrical specimens for compressive strength and splitting tensile strength tests were $10.2 \times 10.2 \times 20.3 \mathrm{~cm}(4 \times 4 \times 8 \mathrm{in}$.), and concrete beams for modulus of rupture tests were $10.2 \times 10.2 \times 35.6 \mathrm{~cm}(4 \times 4 \times$ 14 in.). Three specimens for each test at different ages were used. The strength tests on hardened concrete were performed at 7,28, and 90 days. The Coefficient of Thermal Expansion (COTE) test was performed according to AASHTO T336.

\section{EVALUATION OF PAVEMENT CONCRETE MIXTURES}

The compressive strength, modulus of rupture, modulus of elasticity, and coefficient of thermal expansion of the pavement concrete mixtures at 28 days are presented in Figures 1 through 4, respectively. The drying shrinkage of the pavement concrete mixtures at 182 days are presented in Figure 5. 

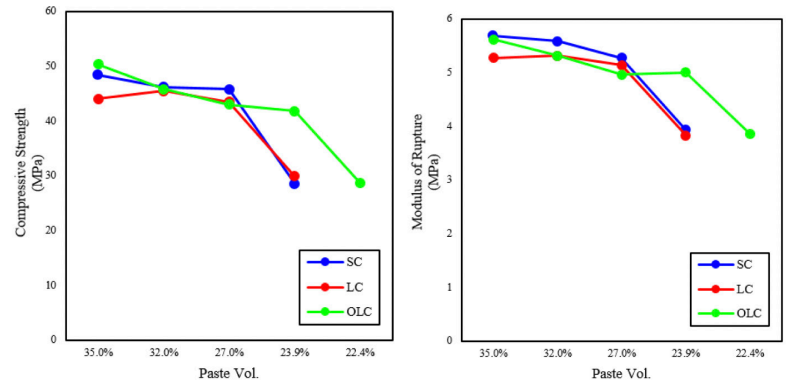

Figure 1 Compressive Strength of the Pavement Mixtures at 28 days

Figure 2 Modulus of Rupture of the Pavement Mixtures at 28 days

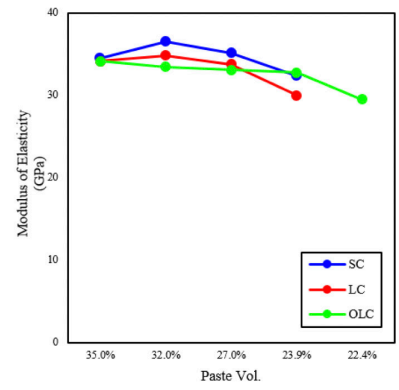

Figure 3 Modulus of Elasticity of the Pavement Mixtures at 28 days

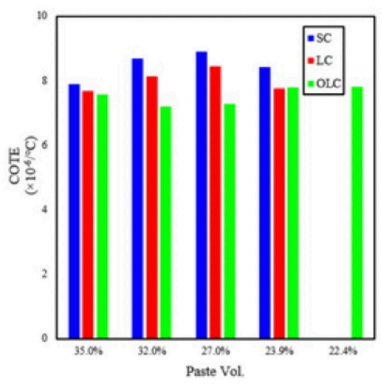

Figure 4 Coefficient of Thermal Expansion of the Pavement Concrete at 28 days

The main findings from the testing program on the pavement concrete mixtures are as follows:

1. The compressive strength, modulus of rupture, modulus of elasticity, coefficient of thermal expansion of the concrete mixes using Type I/II cement, and the concrete mixes using Type IL cement were similar to one another.

2. The concrete mixes using with OAG (OLC mixes) showed lower moduli of elasticity and lower coefficients of thermal expansion, which would result in lower thermalload-induced stresses in concrete pavement slabs, and thus potentially better performance.

3. The drying shrinkage of the concrete using Type IL cement was slightly higher than that using Type I/II cement.

4. The concrete mixes using OAG showed lower drying shrinkage, which would indicate better performance in structural concrete as well as pavement concrete.

5. The cementitious material content of pavement concrete can be reduced to some extent without loss in fresh concrete workability and hardened concrete strength and durability. When the concrete aggregate gradation was optimized, the reduction in cementitious content could be further increased. 
Figure 5: Drying Shrinkage of the Pavement Mixtures at 182 days

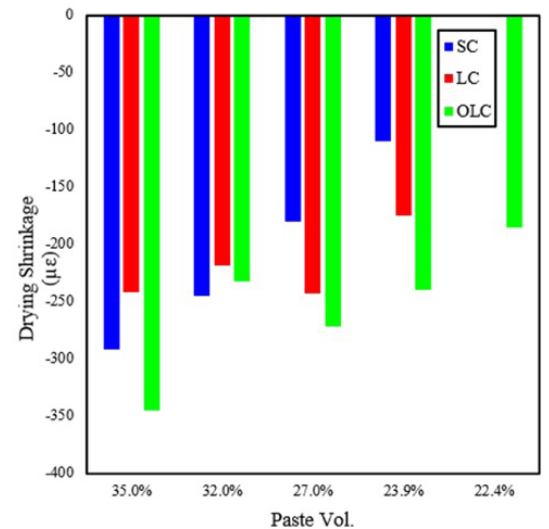

6. Portland-limestone cement (Type IL) containing 12\% limestone powder can be used as a substitute for ordinary Portland cement (Type I/II) in pavement concrete with no loss in fresh concrete workability, or hardened concrete strength and durability.

7. The potential performance of the pavement concrete mixes was evaluated using critical stress analysis. A 3D FEM model developed and validated in a previous pavement project (Tia et al 2017) was used for this purpose. The maximum computed stresses under a critical load-temperature condition were divided by the flexural strengths of the respective concretes to determine the stress-to-strength ratios, which were used to evaluate the performance of the concretes from the laboratory testing program. Results of critical stress analysis indicate that when OAG technique was used, the performance of the pavement concrete was substantially improved, and remained unchanged as the cementitious paste volume was reduced to $22.5 \%$.

\section{EVALUATION OF STRUCTURAL CONCRETE MIXTURES}

The compressive strength, modulus of rupture, modulus of elasticity, and coefficient of thermal expansion of the structural concretes are presented in Tables 4 through 7 , respectively. The drying shrinkage of the structural concrete mixtures are presented in Table 8.

Table 4: Compressive Strength of the Structural Concrete Mixtures

\begin{tabular}{|c|c|c|c|c|c|c|c|c|c|c|c|c|}
\hline (MPa) & \multicolumn{12}{|c|}{ Paste Volume (\%) } \\
\hline Curing & \multicolumn{3}{|c|}{$35.0 \%$} & \multicolumn{3}{|c|}{$32.0 \%$} & \multicolumn{3}{|c|}{$27.0 \%$} & \multicolumn{3}{|c|}{$23.9 \%$} \\
\hline Time(days) & $\mathrm{SC}$ & LC & OLC & $\mathrm{SC}$ & LC & OLC & $\mathrm{SC}$ & LC & OLC & $\mathrm{SC}$ & LC & OLC \\
\hline 7 & 35.2 & 33.2 & 31.0 & 40.1 & 33.0 & 30.5 & 42.9 & 31.6 & 33.5 & 47.4 & 31.6 & 31.2 \\
\hline 28 & 43.0 & 41.0 & 40.7 & 48.9 & 43.3 & 37.8 & 52.7 & 39.4 & 41.0 & 58.2 & 39.4 & 40.3 \\
\hline 91 & 53.2 & 53.0 & 51.0 & 57.8 & 50.6 & 47.1 & 60.5 & 48.1 & 51.8 & 57.0 & 52.1 & 50.3 \\
\hline 182 & 54.5 & 58.4 & 54.1 & 64.6 & 58.4 & 53.6 & 65.2 & 54.5 & 55.0 & 63.8 & 56.3 & 52.0 \\
\hline
\end{tabular}


Table 5: Modulus of Rupture of the Structural Concrete Mixtures

\begin{tabular}{ccccccccccccc}
\hline (MPa) & \multicolumn{10}{c}{ Paste Volume (\%) } \\
\hline Curing & \multicolumn{3}{c}{$35.0 \%$} & \multicolumn{10}{c}{$32.0 \%$} & \multicolumn{3}{c}{ 27.0\% } & \multicolumn{3}{c}{$23.9 \%$} \\
\cline { 2 - 14 } Time(days) & SC & LC & OLC & SC & LC & OLC & SC & LC & OLC & SC & LC & OLC \\
\hline 7 & 4.6 & 4.5 & 5.0 & 5.2 & 4.5 & 4.6 & 5.0 & 4.4 & 4.5 & 5.5 & 4.3 & 4.3 \\
28 & 5.3 & 5.1 & 5.8 & 5.4 & 5.3 & 5.2 & 5.9 & 4.9 & 5.2 & 6.2 & 5.2 & 5.0 \\
91 & 5.8 & 5.7 & 5.6 & 6.0 & 5.7 & 5.3 & 5.8 & 5.6 & 5.8 & 6.0 & 5.7 & 5.9 \\
182 & 5.8 & 5.6 & 5.5 & 5.8 & 5.7 & 5.3 & 5.7 & 5.8 & 5.8 & 5.9 & 5.7 & 5.9 \\
\hline
\end{tabular}

Table 6: Modulus of Elasticity of the Structural Concrete Mixtures

\begin{tabular}{ccccccccccccc}
\hline$(\mathrm{GPa})$ & \multicolumn{10}{c}{ Paste Volume (\%) } \\
\hline Curing & \multicolumn{3}{c}{$\mathbf{3 5 . 0} \%$} & \multicolumn{1}{c}{$32.0 \%$} & & $27.0 \%$ & & $23.9 \%$ \\
\cline { 2 - 14 } Time(days) & SC & LC & OLC & SC & LC & OLC & SC & LC & OLC & SC & LC & OLC \\
\hline 7 & 27.6 & 28.3 & 25.2 & 31.0 & 28.6 & 26.5 & 33.8 & 30.7 & 29.0 & 34.8 & 29.6 & 29.6 \\
28 & 29.6 & 29.6 & 28.3 & 33.4 & 30.7 & 27.6 & 34.5 & 31.4 & 32.1 & 36.9 & 32.4 & 31.4 \\
91 & 32.4 & 33.1 & 31.4 & 36.9 & 34.1 & 30.7 & 37.9 & 34.8 & 33.8 & 39.6 & 36.5 & 34.1 \\
182 & 33.4 & 35.9 & 32.4 & 37.9 & 35.5 & 31.4 & 38.6 & 36.5 & 35.2 & 40.0 & 38.3 & 35.2 \\
\hline
\end{tabular}

Table 7: Coefficient of Thermal Expansion of the Structural Concrete Mixture

\begin{tabular}{|c|c|c|c|c|c|c|c|c|c|c|c|c|}
\hline$\left(\mu \varepsilon /{ }^{\circ} \mathrm{C}\right)$ & \multicolumn{12}{|c|}{ Paste Volume (\%) } \\
\hline Curing & \multicolumn{3}{|c|}{$35.0 \%$} & \multicolumn{3}{|c|}{$32.0 \%$} & \multicolumn{3}{|c|}{$27.0 \%$} & \multicolumn{3}{|c|}{$23.9 \%$} \\
\hline Time(days) & $\mathrm{SC}$ & LC & OLC & $\mathrm{SC}$ & $\mathrm{LC}$ & OLC & $\mathrm{SC}$ & LC & OLC & $\mathrm{SC}$ & $\mathrm{LC}$ & OLC \\
\hline 28 & 7.59 & 7.43 & 7.88 & 7.53 & 7.52 & 7.23 & 7.60 & 7.70 & 7.36 & 7.32 & 7.15 & 7.45 \\
\hline 182 & 7.83 & 7.86 & 8.41 & 8.05 & 8.17 & 7.58 & 8.12 & 8.53 & 7.34 & 8.17 & 7.88 & 7.06 \\
\hline
\end{tabular}

Table 8: Drying Shrinkage of the Structural Concrete Mixtures

\begin{tabular}{ccccccccccccc}
\hline$(\mu \varepsilon)$ & \multicolumn{10}{c}{ Paste Volume (\%) } \\
\hline Curing & \multicolumn{9}{c}{$35.0 \%$} & \multicolumn{9}{c}{$32.0 \%$} & \multicolumn{3}{c}{$27.0 \%$} & & \multicolumn{3}{c}{$23.9 \%$} \\
\cline { 2 - 14 } Time(days) & SC & LC & OLC & SC & LC & OLC & SC & LC & OLC & SC & LC & OLC \\
\hline 7 & 55 & -13 & -70 & -10 & 83 & -3 & 8 & 10 & -13 & -2 & -2 & 25 \\
28 & 93 & -17 & -100 & -10 & 62 & 28 & 110 & -68 & -30 & 43 & 23 & -13 \\
91 & -260 & -340 & -522 & -233 & -298 & -383 & -185 & -397 & -347 & -203 & -272 & -426 \\
182 & -433 & -412 & -492 & -403 & -387 & -422 & -297 & -483 & -393 & -300 & -387 & -360 \\
\hline
\end{tabular}

The main findings from the testing program on Class IV (Structural) concrete were as follows:

1. The compressive strength of the concrete using Type I/II cement was slightly higher than that using Type IL cement. However, most of the mixes passed the FDOT specification limits, with the exception of a mix with a low paste volume of $22.4 \%$.

2. The modulus of rupture, modulus of elasticity, and coefficient of thermal expansion of the SC mixes using Type I/II cement and LC mixes using Type IL cement were similar to one another.

3. The concrete mixes using Type IL cement with or without the application of OAG technique showed lower modulus of elasticity as compared with the concrete using Type I/II cement. 
4. The drying shrinkage of the concrete might increase when Type IL cement is used to replace Type I/II cement.

5. The cementitious content of structural concrete could be reduced to $25 \%$ without loss in fresh concrete workability and strength and durability of hardened concrete. When the concrete aggregate gradation is enhanced by the OAG technique, the amount of reduction in cementitious content could be further increased.

\section{CONCLUSION AND RECOMMENDATIONS}

The results of laboratory testing program and statistical analysis indicate that the use of Portland-limestone cement (Type IL) as a cement replacement in concrete appears to be not only feasible, but also offers the possibility of improving the performance of concrete. The use of OAG along with the reduction of cement content can improve the properties of the concrete mix.

\section{REFERENCES}

AASHTO (2015). AASHTO M240M/M240, Standard Specification for Blended Hydraulic Cement, American Association of State Highway and Transportation Officials, Washington D.C.

AASHTO (2018). AASHTO M85 Standard Specification for Portland Cement, American Association of State Highway and Transportation Officials, Washington D.C.

ARTBA (2015). Production and Use of Coal Combustion Products in the U.S., American Road and Transportation Builders Association, pp. 28, the USA.

ASTM C150 (2018). Standard Specification for Portland Cement, American Section of the International Association for Testing Materials, Pennsylvania, the USA.

ASTM C595 (2018). Standard Specification for Blended Hydraulic Cement, American Section of the International Association for Testing Materials, Pennsylvania, the USA.

Shilstone, J. M. (1990). Concrete mixture optimization, Concrete International, Vol. 10, pp. 33-39.

Singh, H. (2015). Permeability of concrete mix design, proceedings of 6th national conference on Make in India PMs vision: Role of engineering and management innovations to achieve this vision, India.

Tia, M., Subgranon, T., Kim, K., Medina, R. A. \& Algazlan, A. (2015). Internally Cured Concrete for Pavement and Bridge Deck Applications, Research Report, University of Florida, Florida, the USA.

Tia, M., Kim, K. \& Han, S. (2017). Improved analysis tool for concrete pavement, Research Report, University of Florida, Florida, the USA.

Tritsch, N., Darwin D. \& Browning J. (2005). Evaluating shrinkage and cracking behavior of concrete using restrained ring and free shrinkage tests, Research Report, The University of Kansas Center for Research, Kansas, the USA. 